\title{
Antonomie universileterias
}

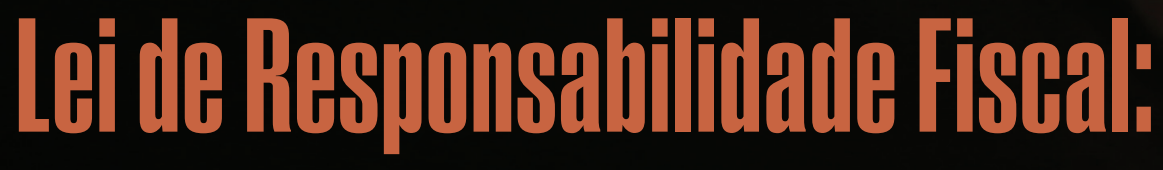

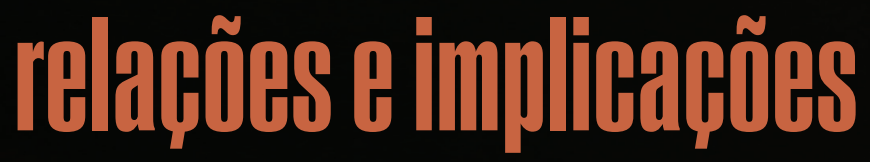

\section{Nina Ranieri}




\section{RESUMO}

No direito brasileiro, a autonomia universitária supõe limites e controles, internos e externos. Este artigo analisa as implicações da Lei de Responsabilidade Fiscal em relação às universidades públicas e sugere a adoção de normas de responsabilidade universitária pelas instituições.

Palavras-chave: autonomia universitária; ensino superior; universidades públicas; Lei de Responsabilidade Fiscal; normas de responsabilidade universitária.

\section{ABSTRACT}

Pursuant to Brazilian law, university autonomy entails internal and external limits and controls. This article analyzes the implications of the Fiscal Responsibility Act as it concerns public universities, and suggests that the institutions adopt liability rules in order to ensure greater accountability.

Keywords: university autonomy; higher education; public universities; Fiscal Responsibility Act; university liability rules. 
AUTONOMIA À PAULISTA:

\section{ESTADO DA ARTE}

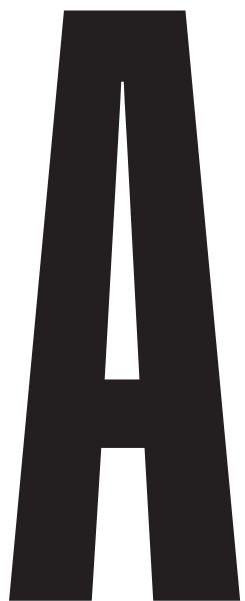

autonomia universitária das universidades estaduais paulistas é uma exclusividade brasileira, uma jabuticaba, por assim dizer. Não há no mundo estrutura legal que assegure o repasse de verbas públicas $(9,57 \%$ do imposto sobre circulação de mercadorias, serviços e transportes - ICMS), em duodécimos mensais, além de amplo espaço de gestão administrativa, financeira e patrimonial combinado com autonomia didático-científica.

O modelo, originalmente previsto no Decreto no $29.598 / 89^{1}$, com fundamento no art. 207 da Constituição Federal ${ }^{2}$, foi sucessivamente manti-

1 "Artigo $1^{\circ}$ - Os órgãos da Administração Centralizada do Estado adotarão procedimentos administrativos cabíveis para viabilizar a autonomia das Universidades do Estado de São Paulo de acordo com os parâmetros deste decreto até que a Constituinte Estadual promulgue a nova Constituição do Estado e que a Assembleia Legislativa decrete a legislação referente ao Sistema de Ensino Superior Paulista. Artigo $2^{\circ}$ - A execução dos orçamentos das Universidades Estaduais Paulistas, no exercício de 1989, obedecerá aos valores fixados no orçamento geral do Estado, do corrente ano, e às demais normas e decretos orçamentários, devendo as liberações mensais de recursos do Tesouro a essas entidades respeitar o percentual global de 8,4\%, da arrecadação do ICMS - quota parte do Estado no mês de referência. $\S 1^{\circ}-\mathrm{Na}$ apuração do percentual indicado no caput deste artigo, não serão consideradas as liberações do Tesouro do Estado originárias de repasse de financiamentos concedidos a projetos específicos das Universidades Estaduais Paulistas. $\S 2^{\circ}$ - Para que o Estado possa cumprir o disposto no artigo 38 das Disposições Transitórias da Constituição do e ampliado, em relação ao montante de recursos que o sustenta, por leis orçamentárias anuais. Entre seus artífices e atores - as universidades públicas, as autoridades do Executivo, do Legislativo (incluído o Tribunal de Contas) e do Judiciário, e Ministério Público - a USP, em particular, teve e tem importante papel no seu aprimoramento jurídico e institucional.

da República Federativa do Brasil, recomenda-se que as despesas com pessoal não excedam a $75 \%$ (setenta e cinco por centro) dos valores liberados pelo Tesouro do Estado às Universidades Estaduais Paulistas. Artigo $3^{\circ}-\mathrm{O}$ Conselho de Reitores das Universidades Estaduais Paulistas baixará normas adicionais fixando os critérios de execução orçamentária das Universidades do Estado de São Paulo, incluindo os relativos à política salarial de seu pessoal docente, técnico e administrativo, observado não só o limite financeiro estabelecido neste decreto como o disposto no artigo 37 da Constituição da República Federativa do Brasil e no artigo 92 inciso VI da vigente Constituição do Estado, com a redação dada pela Emenda Constitucional n ${ }^{\circ} 57$ de 25 de setembro de 1987. Parágrafo único - Caberá ao Conselho de Reitores das Universidades Estaduais Paulistas estabelecer também os percentuais de distribuição do montante de recursos entre as entidades, a serem liberados, mensalmente, pelo Tesouro do Estado na forma e limite estabelecidos no caput do artigo $2^{\circ}$ deste decreto."

2 "Art. 207 - As universidades gozam de autonomia didático-científica, administrativa e de gestão financeira e patrimonial, e obedecerão ao princípio de indissociabilidade entre ensino, pesquisa e extensão".

NINA RANIERI é professora associada do Departamento de Direito do Estado - FD/USP e coordenadora da Cátedra Unesco de Direito à Educação - FD/USP. 
Tomando-se por referência a atual Lei de Diretrizes e Bases da Educação - LDB (Lei 9.394/1996), que discriminou, de forma inédita, algumas das prerrogativas da autonomia universitária ${ }^{3}$, os 25 anos de autonomia à paulista, analisados em perspectiva, apresentam duas fases distintas: a inicial, que vai de 1989 a 1996, e a atual, que cobre o período de 1996 até o presente.

$\mathrm{Na}$ fase inicial, os processos e procedimentos da autonomia universitária ainda não são plenamente conhecidos por seus atores. A jurisprudência tem um papel importante na interpretação do âmbito e limites do art. 207 da Constituição Federal, como já tivera antes da edição da Constituição de 1988. Nessa fase, o âmbito da autonomia universitária é mais importante do que os seus limites.

A fase atual caracteriza-se pela definição dos controles, na qual os limites da atuação autônoma das universidades são mais importantes que o âmbito. Os limites não são claros nem tampouco os controles cabíveis, para nenhum dos atores envolvidos. Para os "os defensores da autonomia", a ênfase está na autonomia, enquanto para "os inconformados", no controle; para outros, ainda, autonomia não existe, é mitologia jurídica. Neste último grupo, incluem-se "os céticos".

São defensores da autonomia as próprias universidades, grande parte dos membros do seu corpo docente e seus funcionários, que enfatizam os aspectos altamente positivos da autonomia, sem perda da referência do controle. Para esse grupo, os avanços acadêmicos, administrativos e financeiros alcançados no período são prova cabal do sucesso do modelo, a despeito de eventuais crises. Em alguns segmentos desse grupo, contudo, percebe-se certa incompreensão acerca do significado da autogestão com recursos públicos, seja devido ao constante apelo ao governo para aumento de repasses financeiros, seja por entenderem que em momentos de crise sempre haverá ajuda governamental.

Os inconformados, de outra parte, concordam com uma autonomia tutelada, consentida,

3 Cf. Lei n 9.394/1996, artigos 53 e 54. destinada a tornar eficiente e facilitar aspectos administrativos, com pouca margem de autonomia financeira. Entendem que os ganhos acadêmicos do período não justificam tão ampla autonomia administrativa e de gestão financeira e patrimonial; acreditam, também, que a universidade poderia fazer mais pela sociedade em que se insere. Tais reclamos são o resultado da presença do Estado numa área em que a promoção do desenvolvimento social e econômico se faz em longo prazo, ao custo de pesados investimentos públicos.

Entre esses se destacam as secretarias de Estado da Fazenda e do Planejamento, para as quais não se justifica a existência, no corpo da administração indireta, de entes com regime financeiro e orçamentário diferenciado a tal ponto. Prova disso foi a edição do Decreto Declaratório $\mathrm{n}^{\mathrm{o}} 1 / 2007^{4}$, que excepcionou as universidades do regime regular do Siafem, dadas as suas peculiaridades de organização e funcionamento, depois de tumultuado período de submissão das universidades àquele regime. Também nos Conselhos Estaduais de Educação (CEE) não há clareza quanto à extensão das prerrogativas da autonomia, seja em matéria curricular (como é o caso da formação de professores), seja na reserva de vagas para alunos egressos da escola pública ou no atendimento de programas governamentais, por exemplo. Esse procedimento desencadeia táticas defensivas, não cooperativas, por parte dos grupos afetados, e tende a relativizar o direito em sua generalidade abstrata.

\footnotetext{
4 O Decreto Declaratório $n^{\circ} 1$, de 30/5/2007, refere-se à não aplicação das disposições dos decretos $n^{\circ} 51.471$, de 2 de janeiro de 2007, e $n^{\circ} 51.660$, de 14 de março de 2007, em vista de a autonomia universitária Ihes conferir regime financeiro e contábil que atende às suas peculiaridades de organização e funcionamento. Diz o seu art. 30: "A execução orçamentária, financeira, patrimonial e contábil das Universidades Públicas Estaduais será realizada em tempo real no Sistema Integrado 51.636, de 9 de março de 2007, sem prejuízo das prerrogativas asseguradas no artigo 54 , da Lei 9.394 , de 20 de dezembro de 1996, que lhes facultam regime financeiro e contábil que atenda às suas peculiaridades de organização e funcionamento. Parágrafo único - No exercício de sua autonomia financeira as Universidades Públicas Estaduais poderão efetuar transferências, quitações e tomar outras providências de ordem orçamentária, financeira e patrimonial necessárias ao seu bom desempenho, na forma do inciso VII, do art. 54, da Lei 9.394, de 20 de dezembro de 1996".
} 


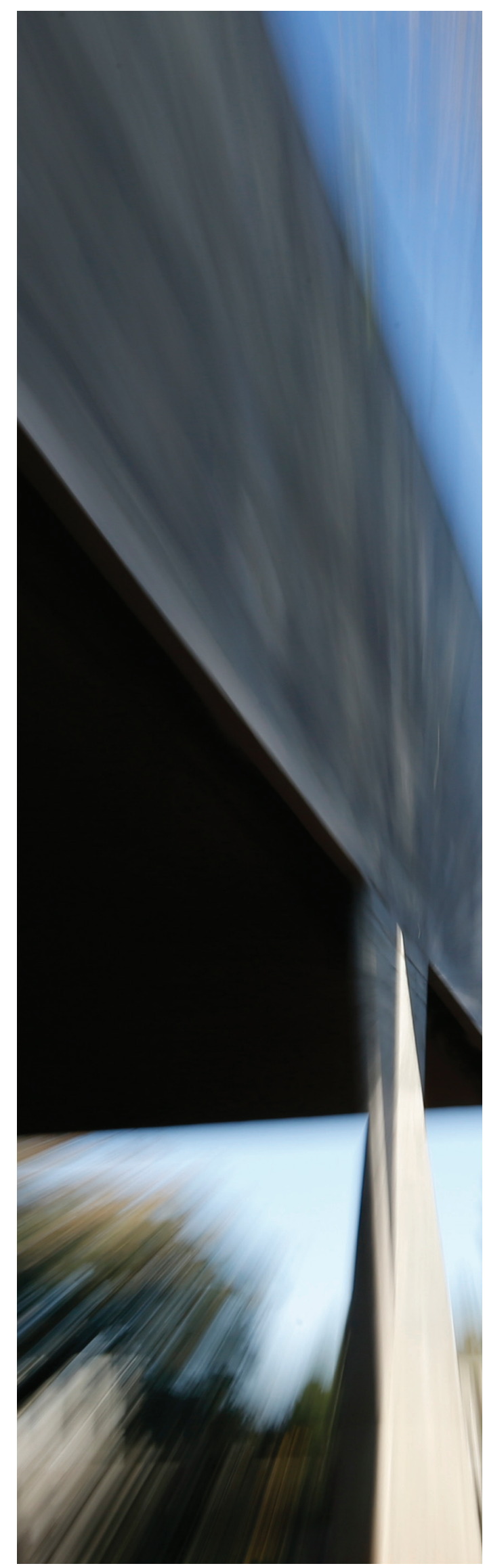

Os céticos, por fim, são aqueles que, acostumados com o centralismo no campo educacional e administrativo, ao invés de tomar a autonomia como a capacidade de se autodirigir, e até mesmo de se autoprover, a consideram potencialmente responsável por eventual diminuição do suporte governamental, particularmente em épocas de crise.

É o que ocorre, de modo geral, nas universidades federais, mas também nas universidades paulistas a partir de 2014 , em virtude da crise financeira provocada pelo alto custo das folhas de pagamento combinado com a diminuição da arrecadação do ICMS.

Tais posições revelam as contradições inerentes à autonomia universitária. A medida da autonomia e do controle, especialmente em matéria administrativa e de gestão financeira e patrimonial, depende não só da ampla compreensão das atividades e vicissitudes universitárias por parte das autoridades governamentais e do Ministério Público como também da responsabilidade dos seus dirigentes e da comunidade universitária.

Sem entrar na análise das motivações que sustentam as posições de cada um dos grupos acima, o fato é que não é simples a compreensão jurídica e institucional da autonomia universitária por três razões principais:

1) A divisão de competências federativas em matéria educacional dificulta a identificação do ente público responsável pelo controle acadêmico das universidades públicas e privadas. Como a maior parte das atribuições compete à União (desde a edição das leis no 9.131 e no 9.192 em 1995, teve início a paulatina ampliação do poder regulamentar federal), há ponderável desconhecimento das competências estaduais, e da legislação vigente, especialmente em matéria de autonomia e controle, por parte dos atores envolvidos no processo educacional. Essa situação permite, com frequente aceitação desses mesmos atores, que a atuação prevalecente do governo federal se faça como se ele fosse o único responsável pela educação superior no país, desobrigando-os de seus próprios encargos. 
2) A extensão e a complexidade da teia normativa que regulamenta a educação superior também dificultam a compreensão da autonomia universitária. A multiplicidade e a provisoriedade das regras, bem como a variabilidade das fontes normativas (o Congresso Nacional, o presidente da República, o Ministério da Educação, o Conselho Nacional de Educação, os Conselhos Estaduais de Educação, o governador, etc.), longe de garantir a eficácia da autonomia universitária, revelam que o Estado não tem clara a medida do controle que deve exercer sobre a educação superior.

3) Finalmente, há pouco conhecimento acerca dos efeitos da autonomia sobre a natureza jurídica das universidades públicas, a despeito de o caput do art. 54 da LDB instituir, para as universidades, figuras de contornos jurídicos específicos, destacadas do conjunto das pessoas administrativas estatais, e marcadas por acentuada feição autonômica. Por outro lado, a finalidade dessas instituições e o repasse de verbas públicas lhes impõem uma série de limitações, todas previstas em lei.

\section{QUE SIGNIFICA SER AUTÔNOMO?}

\section{A AUTONOMIA UNIVERSITÁRIA}

\section{E SEUS LIMITES}

No direito brasileiro, são autônomos os estados, o Distrito Federal e os municípios (CF, art. 18), os partidos políticos (CF, art. 17, § 1), as agências reguladoras $(\mathrm{CF}$, art. 37, § 8º, I, II, III), o Poder Judiciário (CF, art. 99), o Ministério Público (CF, art. 127, § 2º), a Defensoria Pública (CF, art. 134), as universidades (CF, art. 207), as instituições de pesquisa científica e tecnológica (CF, art. 207, § 2), e os índios (CF, art. 231). Evidentemente, o âmbito e os limites da atuação autônoma de cada um desses entes e pessoas variam em função do que a lei pretendeu preservar e facilitar.

Nesse rol, destaco as agências reguladoras e as universidades públicas devido às possibilidades de fracionamento e flexibilização do regime jurídico da administração pública. Com relação às primeiras, a autonomia gerencial, orçamentária e financeira normalmente conferida às autarquias é ampliada mediante celebração de contrato a ser firmado com o poder público, para a fixação de metas de desempenho ${ }^{5}$; para as segundas, a autonomia, prevista no art. 207 da Constituição, confere a elas uma posição peculiar no corpo da administração indireta.

Tal posição foi realçada pela LDB (arts. 53 e 54) ao definir processos como a criação, a organização e a extinção pelas universidades, em sua sede, de cursos e programas de educação superior; a fixação de currículos de cursos e programas; o estabelecimento de planos, programas e projetos de pesquisa científica, produção artística e atividades de extensão; a fixação do número de vagas; a elaboração de estatutos; a atribuição de graus, expedição e registro de diplomas, celebração de contratos, acordos e convênios, aprovação e execução de planos, programas e projetos de investimentos; a administração de rendimentos conforme os dispositivos institucionais; a criação, expansão, modificação e extinção de cursos; a ampliação e diminuição de vagas; a elaboração de programas de cursos; a programação das pesquisas e das atividades de extensão; a contratação e a dispensa de professores; a definição de planos de carreira.

Da mesma forma, é apresentado, no $\S 1^{\circ}$, do art. 54, um elenco particularizado de ações autônomas para as universidades públicas, que se acresce ao do art. 53. Neste estão compreendidas atribuições concernentes à administração de pessoal e à gestão financeira, tais como a elaboração de regulamento funcional, em conformidade com as normas gerais concernentes; a aprovação e execução de planos, projetos e programas de investimentos referentes a obras, serviços e aquisições

\footnotetext{
5 As agências reguladoras - tais como a Agência Nacional de Energia Elétrica (Aneel), a Agência Nacional de Petróleo (ANP) ou a Agência Nacional de Aviação Civil (Anac) - são autarquias de regime especial criadas por lei com a finalidade de regrar determinados serviços, objeto de contrato, autorização ou delegação. Exercem, nessa atividade, poder normativo (e não meramente regulamentar), expresso pela possibilidade de licitar concessionários ou permissionários, outorgar autorizações unilateralmente, definir tarifas, controlar serviços, etc. Seus dirigentes têm mandato fixo e exaram decisões definitivas, dentre outras prerrogativas.
} 
em geral, de acordo com os recursos alocados pelo respectivo poder mantenedor; a elaboração de orçamentos anuais e plurianuais; a adoção de regime financeiro e contábil que atenda às suas peculiaridades de organização e funcionamento; a realização de operações de crédito ou de financiamento, com aprovação do poder competente, para aquisição de bens imóveis, instalações e equipamentos; a realização de transferências, quitações e outras providências de ordem orçamentária, financeira e patrimonial necessárias ao seu bom desempenho.

Ambos são elencos exemplificativos, dada a posição da LDB no sistema jurídico em relação ao art. 207 e aos demais princípios constitucionais que informam a matéria. Aliás, outra não é a letra do caput do citado art. 53 , in verbis: "No exercício de sua autonomia, são asseguradas às universidades, sem prejuízo de outras, as seguintes atribuições [...]". A exemplificação é didática e conveniente, uma vez que esclarece as instituições e o poder público.

Por todas essas razões é que o já mencionado art. 54 da LDB fala em "estatuto jurídico especial" para as universidades públicas, o que confirma não serem elas um ente público como os demais. O que não significa, de nenhum modo, que a autonomia universitária seja um cheque em branco.

A autonomia é poder derivado e deve ser exercido nos limites específicos de sua outorga. É o efeito de uma limitação que a lei impõe a si mesma, de uma abstenção proposital do legislador. Autonomia não é, portanto, soberania, nem significa independência, mas poder funcional derivado, submetido ao ordenamento jurídico que lhe deu causa. Ou seja: o ente que recebe autonomia submete-se, regra geral, ao ordenamento jurídico, ressalvadas algumas situações nas quais o próprio ordenamento jurídico the atribui o poder de se autorregular.

Logo, para as universidades públicas, o regime jurídico administrativo, de direito público, que lhes garante prerrogativas e privilégios (como a liberdade de selecionar e dispensar servidores, de fixar vencimentos, celebrar contratos, etc.), é o mesmo que lhes impõe restrições.

A jurisprudência é pacífica a esse respeito. Conforme assentado pelo Superior Tribunal de Justiça,
"A autonomia universitária, prevista no art. 207 da Constituição Federal, não pode ser interpretada como independência e, muito menos, como soberania. A sua constitucionalização não teve o condão de alterar o seu conceito ou ampliar o seu alcance, nem de afastar as universidades do poder normativo e de controle dos órgãos federais competentes" (MS 3.318-DF).

É o caso da observância das normas orçamentárias e financeiras públicas, que nos termos constitucionais ou legais também se sujeitam a controle contábil, financeiro e orçamentário dos Tribunais de Contas, além de restrições relativas ao uso dos recursos vinculados à educação previstas na $\mathrm{LDB}^{6}$, etc., sujeitando-as a mecanismos formais de controle interno e externo. É desse ângulo que as preocupações com a Lei de Responsabilidade Fiscal - LRF (Lei Complementar 101, de 4/5/2000), no corpo das universidades, vêm ganhando consistência.

6 "Art. 70 - Considerar-se-ão como de manutenção e desenvolvimento do ensino as despesas realizadas com vistas à consecução dos objetivos básicos das instituições educacionais de todos os níveis, compreendendo as que se destinam a: I - remuneração e aperfeiçoamento do pessoal docente e demais profissionais da educação; II - aquisição, manutenção, construção e conservação de instalações e equipamentos necessários ao ensino; III - uso e manutenção de bens e serviços vinculados ao ensino; IV - levantamentos estatísticos, estudos e pesquisas visando precipuamente ao aprimoramento da qualidade e à expansão do ensino; V - realização de atividades-meio necessárias ao funcionamento dos sistemas de ensino; VI - concessão de bolsas de estudo a alunos de escolas públicas e privadas; VII - amortização e custeio de operações de crédito destinadas a atender ao disposto nos incisos deste artigo; VIII - aquisição de material didático-escolar e manutenção de programas de transporte escolar.

Art. 71 - Não constituirão despesas de manutenção e desenvolvimento do ensino aquelas realizadas com: I - pesquisa, quando não vinculada às instituições de ensino, ou, quando efetivada fora dos sistemas de ensino, que não vise, precipuamente, ao aprimoramento de sua qualidade ou à sua expansão; II - subvenção a instituições públicas ou privadas de caráter assistencial, desportivo ou cultural; III-formação de quadros especiais para a administração pública, sejam militares ou civis, inclusive diplomáticos; IV - programas suplementares de alimentação, assistência médico-odontológica, farmacêutica e psicológica, e outras formas de assistência social; V - obras de infraestrutura, ainda que realizadas para beneficiar direta ou indiretamente a rede escolar; VI-pessoal docente e demais trabalhadores da educação, quando em desvio de função ou em atividade alheia à manutenção e desenvolvimento do ensino." 


\section{AS UNIVERSIDADES PÚBLICAS E A LEI DE RESPONSABILIDADE FISCAL}

A LRF estabelece normas de finanças públicas voltadas para a responsabilidade na gestão fiscal, em atendimento aos artigos 165, inciso II do parágrafo 9ª e 169 da Constituição 7

De acordo com o citado art. 165, as normas de gestão financeira e patrimonial alcançam a administração indireta, na qual se incluem as universidades públicas. O art. 169, por sua vez, dá fundamento ao art. 19 da LRF, que limita a $60 \%$ da receita corrente líquida a despesa total com pessoal, em cada período de apuração ${ }^{8}$. Cotejadas tais disposições aos artigos 207 da Constituição e 53 e 54 da LDB, o problema é saber se as normas da LRF incidem sobre a atuação autônoma das universidades.

Várias observações devem ser feitas a esse respeito. Em primeiro lugar, é evidente que as normas de gestão financeira e patrimonial estabelecidas na LRF alcançam as universidades, assim como as normas da ainda vigente Lei 4.320, de 17/3/64, que estatui normas gerais de direito financeiro para a elaboração e controle dos balanços e orçamentos da União, estados, municípios e Distrito Federal.

Ora, se as universidades públicas integram a administração indireta e atuam mediante repasse de verbas públicas, vinculadas à educação, na forma do art. 167, IV da CF, os princípios gerais de responsabilidade de gestão, expressos no art. $1^{\circ}$ da LRF, devem ser observados (princípio da legalidade, art. 37 da CF). São eles: ação plane-

7 "Art. $165[\ldots] \S 9^{\circ}[\ldots]$ II - ... Cabe à Lei Complementar estabelecer normas de gestão financeira e patrimonial da administração direta e indireta, bem como condições para a instituição e funcionamento de Fundos. [...]

Art. 169. A despesa com pessoal ativo e inativo da União, dos Estados, do Distrito Federal e dos Municípios não poderá exceder os limites estabelecidos em lei complementar."

8 "Art. 19. Para os fins do disposto no caput do art. 169 da Constituição, a despesa total com pessoal, em cada período de apuração e em cada ente da Federação, não poderá exceder os percentuais da receita corrente líquida, a seguir discriminados:

I - União: 50\% (cinquenta por cento);

II - Estados: 60\% (sessenta por cento);

III - Municípios: 60\% (sessenta por cento)."

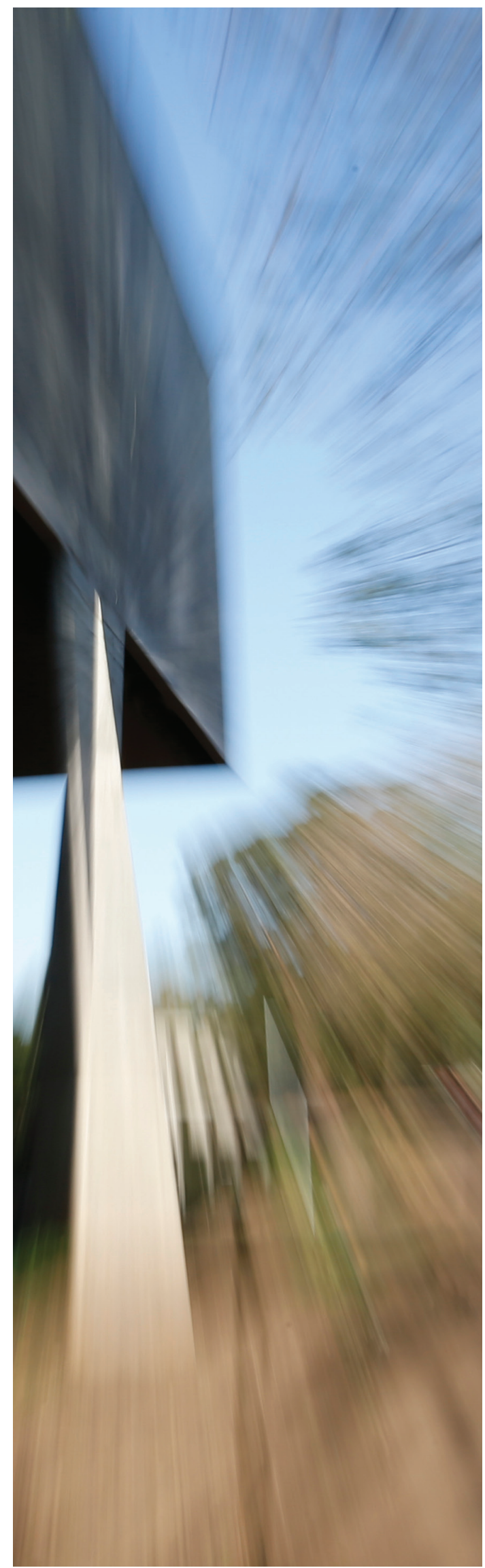


jada e transparente, em que se previnem riscos, se corrigem desvios; equilíbrio das contas mediante o cumprimento de metas de resultados entre receitas e despesas; obediência a limites e condições no que tange à geração de despesas com pessoal, à seguridade social e outras; dívidas consolidada e mobiliária, operações de crédito, inclusive por antecipação de receita, concessão de garantia; e inscrição de restos a pagar. Tais princípios visam a assegurar o equilíbrio entre receitas e despesas, isto é, a garantir que só se gasta o que se tem...

Diferente do equilíbrio orçamentário previsto na Lei 4.320 de 1964, a Lei de Responsabilidade Fiscal traz uma nova noção de equilíbrio para as contas públicas: o equilíbrio das chamadas "contas primárias", traduzido no resultado primário equilibrado. Significa que o equilíbrio a ser buscado deve ser autossustentável, sem operações de crédito e, portanto, sem aumento da dívida pública.

Em segundo lugar, com relação ao art. 19 da LRF, as universidades públicas, como de resto da administração indireta, não são alcançadas diretamente pelo limite ali estabelecido. A norma se dirige aos entes federados - à União, aos estados, aos municípios e ao Distrito Federal - considerada a totalidade dos entes e órgãos que os compõem, e não cada um deles, isoladamente. Ou seja, não são as despesas de pessoal da universidade que estão limitadas a $60 \%$ de sua receita corrente líquida, mas as despesas totais do Estado.

Não se pode perder de vista, porém, que as universidades estão submetidas aos princípios do art. 1․ Logo, embora o limite de $60 \%$ não seja cogente, os princípios da LRF o são, e algum limite deve ser estabelecido. $\mathrm{O}$ equilíbrio entre receitas e despesas é mandatório. Nesse ponto, voltamos à afirmação de que as universidades públicas não são entes públicos como os demais. Basta lembrar que, vinculadas ao princípio da indissociabilidade entre ensino, pesquisa e extensão, os custos do seu pessoal docente são mais onerosos, considerado o regime de trabalho em dedicação exclusiva e integral; sua atividade-fim, ademais, exige mais tempo para sua realização, comparativamente ao tempo de outros entes públicos que não desenvolvem atividade acadêmica.
Em suma, embora seja perfeitamente constitucional e legal a atuação autônoma das universidades públicas estaduais relativamente à fixação do valor dos salários de seus servidores e empregados, independentemente do limite estabelecido no art. 19 da LRF, o equilíbrio entre receitas e despesas deve ser assegurado.

Nesse sentido, foram prolatadas duas decisões pelo Supremo Tribunal Federal acerca da LRF. Uma, relativa à não quebra do princípio federativo (e, portanto, da autonomia dos estados e municípios) e da separação e independência dos poderes do Estado em face do inteiro teor da LRF (Ação Direta de Inconstitucionalidade 2.238, interposta pelos partidos políticos PCB, PT e PSB; Rel. Ilmar Galvão). Outra, mais recente, relativa à expressão "não poderá exceder" do art. 19:

“A expressão 'não poderá exceder', presente no art. 169 da CF, conjugada com o caráter nacional da lei complementar ali mencionada, assentam a noção de marco negativo imposto a todos os membros da Federação, no sentido de que os parâmetros de controle de gastos ali estabelecidos não podem ser ultrapassados, sob pena de se atentar contra o intuito de preservação do equilíbrio orçamentário (receita/despesa) consagrado na norma" (ADI 4.426, Rel. Min. Dias Toffoli, julgamento em 9/2/2011, Plenário, DJE de 18/5/2011).

Pode-se concluir, portanto, que a crescente preocupação com o aprimoramento da gestão pública e a promoção de accountability e publicidade - ou transparência - no setor público exigem a harmonização entre os preceitos da autonomia universitária e a LRF, considerada a sua finalidade.

\section{CONCLUSÕES E RECOMENDAÇÕES}

Tendo em mente a necessidade de harmonização dos preceitos da LRF à vida universitária e de garantir transparência às suas ações, especialmente em momentos de transição reitoral, poderiam ser visualizadas algumas providências a serem adotadas pelas universidades.

Trata-se de um conjunto de recomendações que reproduzem regras já aplicáveis à administração direta e indireta por força da LRF e 
também da lei eleitoral, que poderiam iniciar o debate nos órgãos universitários competentes e também no Cruesp, se for o caso. São elas:

1) Alcançar em cinco anos o limite máximo de $85 \%$ para pagamento da folha de pessoal, considerada a média de três anos; se a meta não for alcançada, a universidade deverá apresentar justificativa ao governo do Estado.

2) Manter reserva financeira suficiente para o pagamento de seis meses de folha de pessoal, no mínimo; se a meta não for alcançada, a universidade deverá apresentar justificativa ao governo do Estado.

3) Incorporação das seguintes normas de responsabilidade fiscal e da lei eleitoral aos estatutos universitários, para vigência nos anos de eleição reitoral:

a) proibição de aumento de despesas com pessoal nos 180 dias antes da posse do novo reitor;

b) proibição de contrair obrigação de despesa que não possa ser cumprida integralmente dentro do mandato em curso, ou que tenha parcelas a serem pagas no exercício seguinte sem que haja suficiente disponibilidade orçamentária para esse efeito;

c) proibição de condutas tendentes a afetar a igualdade de oportunidades entre candidatos nos pleitos eleitorais: fazer ou permitir uso promocional em favor de candidato, de distribuição de bens e cargos da universidade; d) nomear, contratar ou de qualquer forma admitir, demitir sem justa causa, suprimir ou readaptar vantagens ou por outros meios dificultar ou impedir o exercício funcional e, ainda, ex officio, remover, transferir ou exonerar servidor nos três meses que o antecedem e até a posse do reitor, ressalvada a nomeação ou exoneração de cargos em comissão e designação ou dispensa de funções de confiança; nomeação dos aprovados em concursos públicos homologados até o início daquele prazo; e) fazer revisão geral da remuneração dos servidores públicos que exceda a recomposição da perda de seu poder aquisitivo ao longo do ano da eleição, a partir do início dos 180 dias anteriores ao pleito e até a posse do reitor.

4) Possibilidade de ser apresentado anualmente, ao governador, documento acerca do "estado da universidade", assim como das propostas e do planejamento das três universidades estaduais. Esse documento não se confunde com os relatórios solicitados pelo governo, por intermédio da Secretaria de Ciência e Tecnologia; seu propósito seria o de propiciar diálogo direto, fora das instâncias administrativas e burocráticas da administração pública. 